\section{Novel use of Prolene suture for duct delineation during micro- ductectomy}

Shiva Dindyal, Jayant Sharad Vaidya

Department of General and Breast

Surgery, The Whittington, Royal Free and University College Hospitals, London, UK

Classically, microductectomy is performed using a probe inserted via the offending duct to delineate and identify the responsible duct. We propose the use of a 1-0 Prolene (Polypropene blue monofilament nonabsorbable) suture to cannulate the relevant duct. We believe that the use of 1-0 Prolene suture is favourable for duct identification because the blue suture is more apparent when dissecting via an infra-areolar incision and also we believe the malleability of a 1-0 Prolene suture is advantageous in delineating the duct with no distortion of duct anatomy. The use of a rigid probe alters the anatomy and also does not cannulate it to depths that can be achieved with a 1-0 Prolene suture.

Figure 1 shows a breast, which has two secreting ducts both cannulated with 1-0 Prolene suture. Figure 2 shows a Prolene suture delineating a duct and it can clearly be seen that the Prolene suture easily identifies the causative duct.

We propose the use of 1-0 Prolene suture to cannulate a duct during microductectomy because it is easier to use, cheaper and does not distort anatomy.

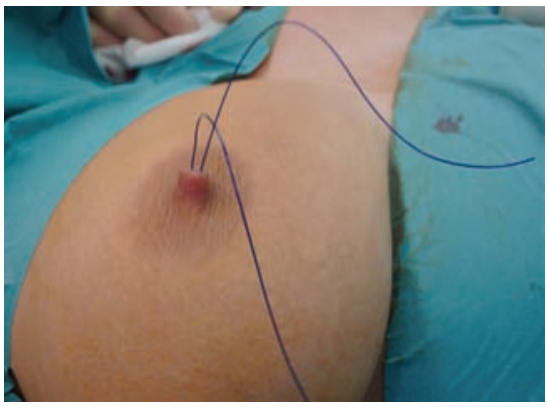

Figure 1. A breast with two secreting ducts both cannulated with 1-0 Prolene suture.

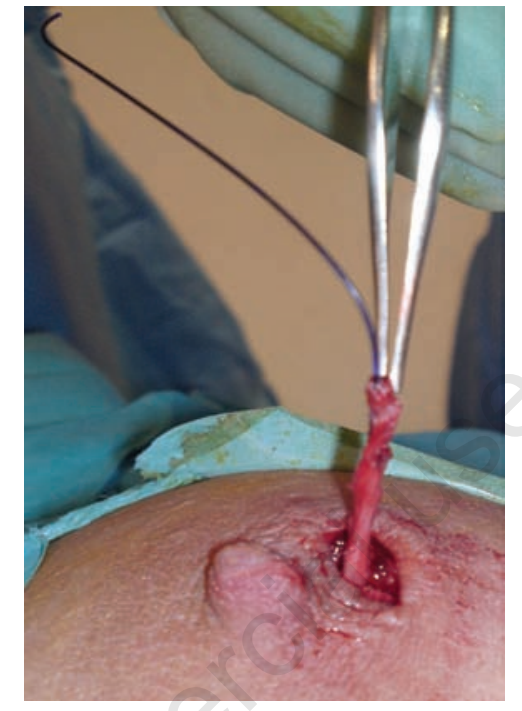

Figure 2. A Prolene suture delineating a duct.
Correspondence: Shiva Dindyal, General Surgery Specialist Registrar, Department of General and Breast Surgery, The Whittington Hospital, The Whittington Hospital NHS Trust, Magdala Avenue, London N19 5NP, UK

E-mail: doctordindyal@hotmail.com

Key words: prolene suture microductectomy.

Received for publication: 16 June 2011. Accepted for publication: 28 August 2011.

This work is licensed under a Creative Commons Attribution NonCommercial 3.0 License (CC BYNC 3.0).

(C) Copyright S. Dindyal and J.S. Vaidya, 2011 Licensee PAGEPress, Italy

Surgical Techniques Development 2011; 1:e11 doi:10.4081/std.2011.e11 